Revista Complutense de Historia de América

ISSN: $1132-8312$

https://dx.doi.org/10.5209/rcha.75317

\title{
El trienio criollo bonaerense en perspectiva transatlántica
}

\author{
Marcela Ternavasio ${ }^{1}$
}

Recibido: 17 de julio de 2020 / Aceptado: 26 de octubre de 2020

Resumen. El presente artículo analiza el experimento reformista desplegado en Buenos Aires entre 1821 y 1824, conocido en la historiografía argentina como la "feliz experiencia". El caso seleccionado formó parte del clima de ideas extendido a escala transatlántica en el marco de las revoluciones liberales europeas. En las reformas aplicadas durante aquel trienio confluyeron diversas vertientes del liberalismo con discursos republicanos e ilustrados. Sus principales objetivos eran modernizar el espacio político, social, económico y cultural y establecer un orden legítimo y estable. Desde una perspectiva de historia política e intelectual, este estudio se concentra en dos focos de análisis. El primero se detiene en la cuestión constitucional y en los lenguajes políticos disponibles en los que se asentó la experiencia reformista rioplatense; el segundo explora los modos de concebir los vínculos entre sociedad y poder político. Ambos focos habilitan a recuperar las íntimas conexiones que exhibió en esos años el gran laboratorio de experimentación que fue el mundo Atlántico y las variaciones que podían adoptar en cada caso los principios revolucionarios, constitucionales y liberales.

Palabras clave: Revolución; liberalismo; constitución; reformas; representación; estado; sociedad; Buenos Aires; siglo XIX.

\section{[en] The Creole Triennium of Buenos Aires from a Transatlantic Perspective}

\begin{abstract}
This article examines the reformist experiment, known in Argentine historiography as the "feliz experiencia" (happy experience), that took place in Buenos Aires between 1821 and 1824. The selected case formed part of the ideological climate that spanned the Atlantic within the context of the European liberal revolutions. Diverse strands of liberalism with republican and enlightened narratives converged in the reforms implemented during that triennium. Their principle objectives were to modernize the political, social, economic and cultural environment and to establish a legitimate and stable order. From a perspective of political and intellectual history, this study centers on two focal points. The first focuses on the constitutional question and the available political languages on which the reformist experiment of the La Plata region was based; the second explores different conceptions of the links between society and political power. Both focal points enable us to recover the close connections showcased in the great experimental laboratory that was the Atlantic world during those years, and the variations that revolutionary, constitutional and liberal principles could adapt in each case.
\end{abstract}

Keywords: Revolution; Liberalism, Constitution; Reforms; Representation; State; Society; Buenos Aires; 19th Century.

Sumario. 1. Introducción. 2. La cuestión constitucional. 3. La Restauración como reserva de experiencia. 4. Sociedad y poder político. 5. Conclusión. 6. Referencias bibliográficas.

Cómo citar: Ternavasio, M. (2021) "El trienio criollo bonaerense en perspectiva transatlántica", en Revista Complutense de Historia de América 47, 21-42.

1 Intituto de Estudios Críticos en Humanidades/CONICET/Uiversidad Nacional de Rosario [Argentina].

E-mail: marcelaternavasio@gmail.com 


\section{Introducción}

En marzo de 1823, Antoine Destutt de Tracy, uno de los exponentes más destacados de la Idéologie francesa, le escribía al entonces ministro de Gobierno y Relaciones Exteriores del estado de Buenos Aires, Bernardino Rivadavia, para felicitarlo por la política de reformas que estaba aplicando "en un país en que, cosa poco común, el gobierno es más liberal que los gobernados"2. El comentario no dejaba de ser halagador para el destinatario de la misiva a la vez que trazaba, de manera implícita, las diferencias que presentaba el Viejo Mundo respecto del rincón austral de América para llevar adelante un plan de transformación que modernizara la sociedad y el orden político. Observado por algunos pensadores europeos como una suerte de globo de ensayo en el marco de lo que se ha dado en llamar la "internacional liberal" conformada en aquellos años, el experimento reformista bonaerense formó parte de ese clima común extendido a escala transatlántica gracias a los intensos vínculos que trazaron viajeros, emigrados, impresos, correspondencias privadas y contactos personales ${ }^{3}$.

Sus condiciones de emergencia no fueron ajenas a las revoluciones liberales ibéricas de 1820 que contribuyeron a poner fin a la guerra de independencia en el Atlántico Sur. El pronunciamiento del teniente coronel Rafael de Riego abortó la empresa de reconquista española destinada a Buenos Aires y la revolución portuguesa -que conminó a la Casa de Braganza a regresar de Río de Janeiro a su antigua sede en Lisboa y que desembocó en la independencia de Brasil- clausuró definitivamente la siempre latente amenaza de una alianza contrarrevolucionaria luso-hispana en América. La situación local rioplatense, por otro lado, también colaboró a llevar adelante la empresa reformista. El colapso del gobierno central de las Provincias Unidas, ocurrido al mes siguiente de la revolución liberal en España, dio lugar al surgimiento de soberanías provinciales independientes bajo formatos republicanos de donde nació el estado de Buenos Aires. En esa escala territorial y social más reducida, entre 1821 y 1824 se desplegó lo que podemos denominar el "trienio criollo bonaerense", conocido en la historiografía argentina como la "feliz experiencia", donde confluyeron diversas vertientes del liberalismo con discursos republicanos e ilustrados para poner en marcha un proceso que reconfiguró el orden político, social, económico y cultural de la ciudad portuaria y su cada vez más expandido espacio rural.

En las siguientes páginas me ocupo de reflexionar sobre el caso de Buenos Aires a partir de dos focos de análisis. El primero se detiene en la cuestión constitucional y en los lenguajes políticos disponibles en los que se asentó la experiencia reformista rioplatense; el segundo explora los modos de concebir los vínculos entre sociedad y poder político. Los focos seleccionados -que no aspiran a un estudio de carácter constitucional y jurídico sino a un examen inscripto en la historia política e intelectual-habilitan a recuperar las íntimas conexiones que exhibió en esos años el gran laboratorio de experimentación que fue el mundo Atlántico y las modulaciones que podían adoptar en cada caso los principios revolucionarios, constitucionales y liberales.

2 Carta de Antoine Destutt de Tracy a Bernardino Rivadavia. París, 10-III-1823. Piccirilli, 1942: 482. La cursiva es nuestra.

3 Sobre la "internacional liberal” véase Isabella, 2009. 


\section{La cuestión constitucional}

Uno de los aspectos del ensayo político bonaerense, a primera vista paradójico, es que el impulso reformista no se plasmó en la sanción de una constitución sino en sucesivas leyes que gradualmente asumieron la calificación de "leyes fundamentales" de la provincia. A pesar de que la Junta de Representantes de Buenos Aires se declaró "extraordinaria y constituyente" el 3 de agosto de 1821, dándose un año de plazo para dictar una constitución, lo cierto es que no se presentó ni discutió un proyecto constitucional ni se sancionó carta orgánica alguna en el ámbito provincial ${ }^{4}$. Para contextualizar esta ausencia es oportuno repasar algunas de las cosmovisiones que circulaban acerca del papel que debía cumplir una constitución escrita para organizar y regular el orden social y político, comenzando por las imágenes que promovió la restitución de la carta gaditana que conminó a Fernando VII a jurar como rey constitucional.

Pocos meses después de producirse en España el pronunciamiento de Riego, el enviado plenipotenciario del gobierno chileno en Europa, Antonio José Irisarri, editó en Londres un periódico titulado El Censor Americano ${ }^{5}$. Dicho periódico publicó agudas reflexiones acerca de la Constitución de España y de las alternativas monárquicas y republicanas para América, sobre las cuales interesa aquí destacar dos puntos. El primero es la imagen crítica y escéptica que expresó respecto del constitucionalismo liberal de la Península: a "los inconvenientes que la constitución española presenta al interés del Nuevo Mundo" se suma el hecho de que "no podrían jamás los Americanos sacar ninguna ventaja de su unión con España bajo un orden de cosas tan desfavorable". Según el editor, "tan lejos de influir la nueva revolución de España en favor de la reunión de los países que se han declarado independientes en el nuevo mundo, sucederá que México, Guatemala y Lima sigan el ejemplo de Venezuela, Nueva Granada, Chile y Buenos Aires"7. La perspectiva se ajustaba bien a la situación del mapa que habían trazado las regiones tempranamente insurgentes que, a esa altura, seguían sus propios derroteros para consolidar sus independencias. El segundo punto atañe al arco temporal trazado por el editor del periódico: “ ¿Creen que nosotros no conocemos que la constitución española no es una constitución americana? ¿Creen, en fin, que en 1820 hemos de recibir como un favor, después de mil victorias, lo que en 1812 recibimos como un agravio?"'. Para ese mapa insurgente, la Constitución de Cádiz regresaba bajo el espejo del agravio y era allí, precisamente, donde se recuperaban las críticas que mereció la carta gaditana en su primera fase constituyente. Tales críticas estaban concentradas en el cuestionamiento al sistema representativo por las desigualdades numéricas entre las provincias peninsulares y americanas, por la exclusión de las castas, por el régimen electoral indirecto en diversos grados y por la implementación de la representación supletoria americana en 1820, tal como había ocurrido una década atrás ${ }^{9}$. Aunque el periódico no asumía la defensa de un orden republicano para los nacientes estados americanos, sino una

\footnotetext{
Registro Oficial de Buenos Aires, 1821: 10-11.

El Censor Americano ha sido recientemente publicado por el Centro de Investigaciones Diego Barros Arana con un Prefacio de Iván Jacsick. El Censor Americano, 2019.

"Estado de la revolución de América", El Censor Americano, n 1, VII-1820, 53.

Ibídem: 53

"Política", El Censor Americano, n 3, IX-1820, 219.

"Reflexiones sobre la presente Constitución de España", Ibídem: 61-70.
} 
monarquía constitucional templada que seguía el modelo británico, la demoledora reprobación que hizo de la Constitución de Cádiz replicaba el clima de debate desplegado en el Río de la Plata durante la década revolucionaria.

¿Cuál fue el itinerario que siguió ese debate en el caso que aquí nos ocupa? Las razones esgrimidas en Buenos Aires durante la fase constituyente peninsular para justificar el rechazo a participar de las Cortes fueron las mismas que reproducía $E l$ Censor Americano. Pero una vez sancionada la Constitución en 1812, a dichas razones se agregó otra que ponía en evidencia las disputas en torno a la definición del sujeto de imputación de la soberanía, como expresó la Gazeta Ministerial -órgano de prensa del gobierno rioplatense- que sometía a dura crítica el principio de la "soberanía de la Nación" establecido en la carta española para ambos hemisferios: "Estas doctrinas que tan escandalosas eran al común de los pueblos, hoy las vemos erigidas en dogma político y publicadas como leyes fundamentales de su gobierno. Ya todos saben que el único origen de toda autoridad pública es la voluntad de los pueblos" ". La representación política y el autogobierno de los cuerpos territoriales eran los temas candentes en una coyuntura atravesada por la incertidumbre respecto del futuro de la monarquía hispánica y de los territorios ultramarinos; temas que quedaron desplazados a partir de la restauración absolutista de Fernando VII, cuando la experiencia gaditana comenzó a resignificarse en el ámbito local rioplatense tanto en el registro de los modelos constitucionales alternativos como en clave política.

Después de declararse la independencia de las Provincias Unidas en julio de 1816, y frente al desafío que implicaba organizar el nuevo orden emancipado, los debates en torno a las formas de gobierno ocuparon el centro de la escena ${ }^{11}$. Si bien el Directorio a cargo del poder ejecutivo y el congreso constituyente promovieron la alternativa de una monarquía constitucional, el modelo gaditano no figuraba entre los preferentes. El periódico porteño El Censor procuraba resumir el abanico de opciones en los siguientes términos: "Observo algunos inclinados a la constitución inglesa, otros se inclinan a la norteamericana, y no falta quien descubra el mejor acierto en la abolida en España por el partido que domina" ${ }^{2}$. El menú planteado reflejaba selectivamente el enfrentamiento entre quienes defendían el modelo monárquico constitucional y quienes propugnaban el modelo republicano, con formatos más o menos centralistas o (con)federales. En ese abanico, sin embargo, la positiva valoración que hacía el editor de El Censor -el emigrado liberal Antonio José Valdez, diputado por Cuba en las Cortes de Cádiz- de la Constitución de 1812, a la que consideraba un modelo de "democracia monárquica", emergía como una voz solitaria ${ }^{13}$.

A esa altura, el rechazo del ensayo constituyente español no se detenía en razones de ingeniería jurídica sino en argumentos políticos. Así lo dejó en evidencia el editor de La Crónica Argentina, Vicente Pazos Silva, vocero de los grupos republicanos de oposición al gobierno directorial, quien acusaba a Valdez de haber sido parte de unas Cortes "que os declararon insurgentes, bloquearon los puertos de la Unión y votaron contra vosotros la expedición a Montevideo en 1813 a sojuzgaros"14. Pazos Silva continuaba su diatriba recordándoles a los lectores "que el período de la existencia

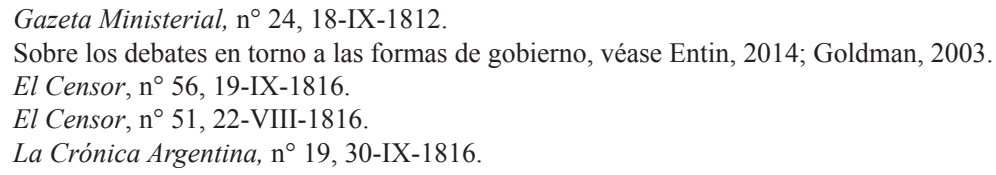


de las Cortes, no obstante, la liberalidad que ahora se atribuyen por esencia, fue el más violento contra los derechos de la América" y el que preparó el camino a la restitución de la tiranía ${ }^{15}$. En esa breve referencia, La Crónica no hacía más que recuperar una memoria reciente que, en el Río de la Plata, identificaba la experiencia de las Cortes de Cádiz con el despotismo metropolitano. Así, el repertorio liberal gaditano, aunque contemplado a la hora de diseñar algunos de los dispositivos gubernamentales de aquellos años, no podía ser reivindicado públicamente por estar asociado en el imaginario colectivo con un componente colonialista y con una liturgia revolucionaria que gradualmente convirtió a España en el enemigo sobre el cual se construyó la identidad patriótica ${ }^{16}$.

En ese clima de debate, en el que la cuestión constitucional quedaba subordinada a la definición de la forma de gobierno (monarquía versus república) y del sujeto de imputación soberana (pueblos versus nación), la sanción de la Constitución de 1819 para las Provincias Unidas representó un punto de inflexión. Se trataba de la primera carta orgánica dictada luego de la revolución de 1810, cuya factura presentaba un llamativo silencio. Tal como ha destacado Natalio Botana, en los artículos que la componían no se definió la forma de gobierno ni se hizo mención alguna al sustantivo república ni al adjetivo republicano; un silencio que no fue ajeno a las vías diplomáticas que el gobierno estaba explorando de manera reservada en las Cortes europeas para coronar a un príncipe de linaje a la cabeza del nuevo orden constitucional ${ }^{17}$. Pero a pesar de este silencio, los diputados hacían explícita su inclinación por dos principios de organización política. El primero era la preferencia por el modelo más prestigioso del momento que representaba el gobierno mixto británico, convertido en paradigma de equilibrio de poderes y de estabilidad política; el segundo, la instauración de un régimen centralista que la constitución abrazó de manera explícita y que profundizó las preexistentes disputas con los pueblos que reclamaban una república de tipo confederal hasta derivar en el derrocamiento del poder central por parte de las fuerzas federales de las provincias del Litoral en febrero de 1820.

La reimplantación de la carta gaditana se produjo, pues, en ese clima de altísima conflictividad que terminó desmoronando al primer y único ensayo constitucional de las Provincias Unidas. Así, mientras la dimensión universalista del temprano constitucionalismo hispánico se afianzaba como movimiento transnacional, según destaca Javier Fernández Sebastián, en el Río de la Plata el liberalismo español arrastraba un pronunciado desprestigio ${ }^{18}$. Las primeras noticias sobre los acontecimientos ocurridos en Cabeza de San Juan comenzaron a arribar a Buenos Aires dos meses después y la Gazeta fue informando de los sucesos de la Península de manera escueta, sin prestarle demasiada atención, en contraste con el protagonismo que asumieron en sus páginas los vertiginosos hechos locales. En el mes de junio, una vez confirmado que el monarca se había visto obligado a aceptar la constitución, el periódico celebró las novedades de lo que calificó como "una completa revolución”: “iQué triunfo para la libertad, arrancar respeto y homenaje del tirano que osó hollarla con la planta más impía que ha pisado las gradas sangrientas del trono!" "19. La misma Gazeta se

\footnotetext{
Ibídem.

Los debates en torno a la Constitución de Cádiz y su impacto en el Río de la Plata los desarrollé in extenso en Ternavasio, 2007. 
encargó en aquellos días de someter a furiosas críticas los planes monárquicos del gobierno directorial recientemente caído al que acusó de querer imponer el orden a costa de la libertad:

Pero tranquilidad, quietud, paz de muertos en un estado como el nuestro es una quimera política, que no puede dejar de producir el absoluto aniquilamiento del espíritu público, la desaparición de la libertad, y demás sensibles objetos, que se han seguido al memorando decreto de $1^{\circ}$ de Agosto de 1817 [sic, fe de erratas: 1816] de nuestro árbitro soberano, el Soberano Congreso Nacional -Fin a la Revolución, principio al Orden ${ }^{20}$.

Lo sucedido simultáneamente a ambos lados del Atlántico venía a reforzar la idea de que si en un sistema monárquico absoluto la vía constitucional era el repertorio más adecuado para limitar los poderes omnímodos de los reyes, en el territorio rioplatense recién emancipado, con pueblos movilizados tras la politización guerrera que produjo una vertiginosa desacralización de la figura del rey $\mathrm{y}$, junto con ella, un rechazo visceral ante cualquier forma de gobierno monárquico aunque éste fuera limitado y constitucional, la república se imponía en los hechos y dejaba pendiente el dilema de su futura organización.

En ese contexto, la aparente paradoja antes señalada -de que durante el trienio bonaerense la dirigencia política no demostrara interés en el tema constitucionalpuede encuadrarse mejor si consideramos las dimensiones brevemente descriptas hasta aquí. Por un lado, las experiencias precedentes no dejaban un zócalo de consensos mínimos sobre el papel de las ingenierías constitucionales en la construcción de un orden político equilibrado y estable. Los ensayos sucedidos en Europa entre la Revolución Francesa y las revoluciones liberales que recién comenzaban no exhibían resultados alentadores, mientras que las dos asambleas constituyentes realizadas en el Río de la Plata (1813-1815 y 1816-1820) habían concluido de manera drástica, con revoluciones que derrocaron a los gobiernos de turno y que clausuraron los congresos sometiendo a varios de sus diputados a juicios posteriores y, en muchos casos, a sufrir destierros ${ }^{21}$. Por otro lado, la reducción de la escala territorial de los cuerpos soberanos surgidos del colapso del poder central también incidió en el derrotero adoptado por el naciente estado de Buenos Aires. Si bien dicha reducción, y una vez desplazado el umbral de la alternativa monárquica, abría la posibilidad de transitar más fácilmente por un ensayo republicano plasmado en una constitución, existían otras variables que podían dejar en suspenso la segunda premisa.

En tal sentido, el contrapunto con la experiencia de Estados Unidos puede iluminar el asunto ${ }^{22}$. Las representaciones que sobre el experimento constitucional norteamericano circulaban en el espacio público porteño eran por cierto variadas, pero coincidían en valoraciones positivas respecto de la estabilidad alcanzada por las ex colonias británicas. Pero hay un punto adicional en esas representaciones que atañe directamente a nuestro argumento. La prensa señalaba que una de las diferencias

\footnotetext{
20 Gazeta Extraordinaria de Buenos Aires, 18-IV-1820.

21 Sobre los juicios perpetrados a los miembros de los gobiernos rioplatenses entre 1810 y 1820 , véase Polastrelli, 2019.

22 Véase Saguir, 2020.
} 
existentes entre la república del norte y el Río de la Plata en la década de 1810 residía en que los "Estados Unidos de América, divididos al declarar su independencia en trece estados diversos, cada uno estableció desde luego su gobierno particular" y que una vez reunidos en un Congreso Constituyente "ya se hallaban organizados los gobiernos individuales" 23 .

¿La situación de 1820 habilitaba a seguir la ruta del norte? Las nuevas repúblicas provinciales se hallaban, de hecho, en un momento confederal y ante el desafío de organizar sus respectivos gobiernos independientes ${ }^{24}$. La mayoría de ellas actuó en esa dirección y, como lo hicieron los gobiernos estaduales norteamericanos entre la declaración de independencia de 1776 y la asamblea de Filadelfia de 1787, fueron sancionando sus propias constituciones o reglamentos constitucionales en formatos republicanos, con sistemas representativos de base electoral, legislaturas unicamerales y gobernadores a cargo de los poderes ejecutivos. La diferencia que trazaron con Buenos Aires -o que Buenos Aires estableció respecto de ellas- no fue ajena a la centralidad que tenía la provincia más poderosa en el concierto de las fragmentadas jurisdicciones rioplatenses, para las cuales dictar una constitución significaba consolidar sus instituciones locales frente a cualquier intento de nacionalización del cuerpo político que intentara avasallar el principio de autogobierno de las partes. En tal proyección, la dirigencia de la ex capital virreinal podía desentenderse, al menos por un tiempo, de los altos costos de liderar una unidad interprovincial para pacificar su propio territorio, gozar de los recursos fiscales que proveía la Aduana del puerto de ultramar y afianzar sus fronteras para la expansión económica de su campaña. El gobierno de Buenos Aires se colocaba, así, como heredero del poder central caído y como protagonista de cualquier emprendimiento constitucional a nivel nacional, a la vez que no se sentía compelido a darse una carta orgánica a nivel provincial que lo protegiera de ese futuro emprendimiento.

Ahora bien, si lo dicho hasta aquí apunta a explicar las posibles razones fácticas del desinterés constitucional de quienes lideraron la agenda reformista del trienio bonaerense, es preciso contemplar también, a nivel más general, un aspecto sobre el cual vienen insistiendo los especialistas de la nueva historia crítica del derecho al postular las continuidades del gobierno jurisdiccionalista de la tradición legal hispana. En este sentido, en una reciente contribución, Alejandro Agüero afirma que los textos provinciales posteriores a 1820 siguen el patrón que en los últimos años se ha identificado como constitucionalismo hispano. Desde esta perspectiva, dichos textos habrían surgido como intentos de formalizar tradiciones e identidades territoriales procedentes de la época colonial más que como "actos constituyentes que puedan calificarse de originarios" $" 25$. Si bien esta interpretación no deja de despertar controversias en la historiografía especializada del período, el autor no niega otras influencias y admite los intentos de armonizar la vieja tradición jurídica con las innovaciones. En el marco de ese difícil equilibrio entre lo viejo y lo nuevo, a continuación, nos detendremos en las innovaciones que venían a dotar al flamante ensayo de construcción estatal bonaerense de lenguajes y dispositivos políticos que avalaban la salida adoptada.

\footnotetext{
23 El Censor, $n^{\circ}$ 56, 19-IX-1816.

24 Sobre la formación de las repúblicas provinciales véase Ternavasio, 2009. Sobre la noción de estados-provincias soberanos véase Chiaramonte, 1997.

25 Agüero, 2019: 155-156.
} 


\section{La Restauración como reserva de experiencia}

La elite dirigente de Buenos Aires contó con incentivos adicionales para reformar y legislar sin constitucionalizar el orden político. Además de los antecedentes frustrados y altamente conflictivos en el propio territorio y en el más amplio espacio Atlántico, disponía de una caja de herramientas que abría la posibilidad de avanzar por un camino heterodoxo que, sin atarse a recetas rígidas, pudiera combinar principios de distintas constelaciones ideológicas con miradas pragmáticas sobre la realidad local. Principios y lenguajes, por otro lado, que dejaron su impronta en el set de medidas aplicadas y diseñadas por un estrecho círculo de dirigentes que habían alcanzado diferentes posiciones y cargos en la década revolucionaria y que compartían un ideario común con publicistas y letrados que contribuyeron a promoverlas ${ }^{26}$.

Entre los personajes destacados de la llamada "feliz experiencia" sobresalen dos figuras que ocuparon cargos ministeriales claves en la provincia: el ya mencionado Bernardino Rivadavia en la cartera de Gobierno y Manuel José García en Hacienda. Compañeros de estudios en el Real Colegio San Carlos de Buenos Aires durante los últimos años de la colonia, ambos se iniciaron en la carrera política abierta por la revolución: el primero como secretario del primer Triunvirato en 1811 y el segundo como secretario de Hacienda en 1813. Ambos, además, encabezaron las dos misiones diplomáticas más prolongadas y significativas que el gobierno de las Provincias Unidas envió al extranjero entre 1815 y 1820: el destino de Rivadavia fue Europa y el de García, Río de Janeiro. Una vez concluidas sus misiones, al desintegrarse el gobierno central que las había instruido, fueron designados por el naciente estado de Buenos Aires en los ministerios mencionados.

Detengámonos brevemente en los itinerarios de estos dos personajes cuando cumplieron sus misiones como plenipotenciarios durante la primera Restauración europea y estuvieron al frente de las negociaciones que el gobierno directorial inició o apoyó para instaurar una monarquía constitucional en el Río de la Plata. No viene al caso describir esas laberínticas tratativas, de las que se ocupó la historiografía política y diplomática, sino destacar que desde los diferentes destinos que les tocó en suerte observaron los acontecimientos y alternativas que presentaba el clima legitimista y conservador posnapoleónico y fueron testigos de los debates políticos e ideológicos desarrollados a ambos lados del Atlántico. En el caso de García, su destino brasileño lo conectó con la vida cortesana de Río de Janeiro, con representantes de las legaciones diplomáticas europeas y con emigrados hispanoamericanos de todos los signos políticos e ideológicos ${ }^{27}$. El ambiente carioca, sin embargo, no era comparable al de otras Cortes europeas. Si bien era un centro por el que circulaban noticias e impresos de diversa procedencia, el control ejercido por los funcionarios de la Corona portuguesa hacía que las prácticas de sociabilidad no se mostraran muy propicias para mantener un abierto debate de ideas ${ }^{28}$. En este sentido, la vida en la nueva sede de la monarquía lusa difería de la que podía tener Rivadavia en Europa, quien alternó su prolongada estancia entre Londres y París. Si bien el clima conservador de la Restauración permeaba todos los rincones del Viejo Mundo, el plenipotenciario

\footnotetext{
26 Halperin Donghi, 1979.

27 Documentos inéditos acerca de la misión del Dr. D. Manuel José García diputado de las "Provincias Unidas en la Corte del Janeiro, 1883.

28 Véase Pimenta, 2017.
} 
criollo pudo trabar vínculos con personajes de relieve intelectual que representaban las posiciones más críticas a ese ambiente dominante, tales como Jeremy Bentham, James Mill, Antoine Destutt de Tracy o el abate Dominique de Pradt.

Los contactos de Rivadavia con los mayores exponentes del utilitarismo británico y de la Ideologie francesa han sido objeto de contribuciones historiográficas que demuestran -como lo hace Klaus Gallo en la más reciente y actualizada biografía del personaje- los horizontes de ideas de los que se fue nutriendo durante su estancia europea $^{29}$. Los vínculos que el diplomático criollo estrechó con Bentham a través de encuentros personales e intercambios de correspondencia, impresos y traducciones figuran entre los más significativos. El representante del utilitarismo británico le enviaba y recomendaba sus obras, subrayando su utilidad para los hombres de Estado, como lo hizo en 1818 con los Tratados de Legislación civil y penal ${ }^{30}$; le aconsejaba en su correspondencia no insistir en la búsqueda de un príncipe de linaje por no ser la monarquía constitucional la forma de gobierno adecuada para las provincias independientes; o le sugería ponerse en contacto con algunos españoles que habían participado en el gobierno de José Bonaparte exiliados en ese momento en Francia ${ }^{31}$. A su vez, durante sus años de residencia en París, Rivadavia estableció contacto con Tracy, quien ofrecía otras miradas para impugnar el orden legitimista, por cuanto los ideologues franceses no profesaban una completa adhesión a la tradición liberal inglesa; impugnaciones que en la coyuntura de la Restauración radicalizaron sus principios al reafirmar el republicanismo y buscar conciliar las nociones de utilidad y bienestar ${ }^{32}$.

En esos ambientes, no solo se elaboraban nuevas respuestas para aspirar a un orden político deseable y posible que, sobre la base de las modernas libertades, evitara los excesos de la revolución, sino que los exponentes de la heterogénea constelación liberal europea que frecuentaba Rivadavia apoyaban la causa independentista americana. Son bien conocidas, en este sentido, las relaciones de Bentham con los liberales españoles a quienes les envió su Rid yourself of Ultramaria (como asimismo a Rivadavia cuando estaba a punto de regresar al Río de la Plata), una obra en la que reescribe en 1820 los argumentos vertidos en 1791 destinados a los líderes revolucionarios franceses con los cuales buscaba persuadir de los inconvenientes de mantener un sistema colonial, oneroso para las metrópolis como perjudicial para las posesiones ultramarinas ${ }^{33}$. Son conocidos, también, los contactos que Bentham mantuvo con las dos revoluciones ibéricas del Trienio (y no solo con ellas), los diversos escritos dedicados a los liberales portugueses y españoles y sus ofertas para elaborar proyectos codificadores ${ }^{34}$. Conexiones todas que involucraban a un universo cosmopolita que se extendía desde Rusia, Grecia, Italia, Inglaterra, la Península Ibérica hasta los distintos rincones de América.

Las trayectorias que trazaron García y Rivadavia, si bien en contextos diferentes, contribuyen a exhibir en sus tránsitos de diplomáticos a ministros de estado dos cuestiones que es oportuno destacar. La primera es que supieron abandonar rápidamente los planes monárquicos en los que se involucraron como plenipotenciarios

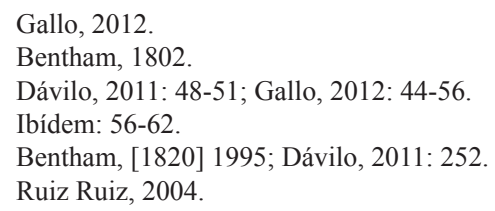


para convertirse en paladines del experimento republicano del gobierno de Buenos Aires a cargo del general Martín Rodríguez, gobernador designado en plena crisis de 1820. Dicha conversión expresaba la ductilidad que demostraron tener frente al clima que encontraron luego de un lustro de ausencia, donde no era difícil percibir que el umbral del futuro inmediato no podía sino ser republicano. La segunda cuestión atañe a la pregunta acerca de cómo incidieron las experiencias precedentes de ambos personajes en la caja de herramientas utilizada en la gestión gubernamental que los reunió a su regreso. Aunque las respuestas a este interrogante sólo pueden ser parciales, es preciso recordar que ambos se repartieron sus órbitas de influencia para poner a disposición la expertise que poseían en los dos campos que requerían soluciones más urgentes.

García, que había desempeñado funciones de Hacienda, tuvo un destacado papel en la organización y modernización de la estructura administrativa y económica de la provincia que le permitió salir de la devastadora situación que había dejado como herencia la guerra revolucionaria y de independencia ${ }^{35}$. Pero el crecimiento económico logrado en esos años requirió previamente ordenar y estabilizar al nuevo gobierno en el complicado escenario que dejaba la crisis de 1820. En este plano, los lineamientos políticos centrales del proceso reformista estuvieron a cargo de Rivadavia, quien supo capitalizar la reserva de experiencia acumulada en los prolongados períodos de "ocios diplomáticos" que vivió durante su misión europea, donde frecuentó a los círculos y redes políticas ya mencionadas. Si bien el protagonismo que exhibió desde la cartera de Gobierno -que llevó a identificar al trienio como el "período rivadaviano"- no fue excluyente ni debe opacar las intervenciones de los dirigentes que conformaron el llamado Partido del Orden o Partido de la Reforma, las conexiones trazadas por el entonces plenipotenciario durante el sexenio de la Restauración constituyen un buen punto de partida para penetrar en las lecturas y diagnósticos que mereció la política local a la hora de construir el nuevo estado provincial que surgía de las cenizas del poder central.

La primera clave de lectura remite a la cuestión constitucional desarrollada en el anterior apartado. La elite dirigente porteña contaba ahora con el aval de argumentos elaborados en los gabinetes de producción intelectual europea para apoyar la idea de que se podía marchar progresivamente en el proceso de institucionalización política sin necesidad de fijar una carta orgánica. La propuesta de un gradualismo institucionalizador estaba en línea con la recomendación realizada por Jeremy Bentham en su Tratado de Legislación Civil y Penal en el que otorgaba escasa importancia a la constitución como pieza jurídica para privilegiar la iniciativa de una legislación minuciosa capaz de encuadrar de manera racional las conductas humanas. Una propuesta que se adaptaba muy bien a la situación imperante en Buenos Aires y que tomaba distancia de lo que ocurría en otras provincias como asimismo del repertorio que simultáneamente se desarrollaba en las revoluciones liberales europeas y en otras regiones de Hispanoamérica, donde la sanción de una carta constitucional emergía como fundante del nuevo orden instaurado.

La dirigencia porteña optó, pues, de manera deliberada por avanzar progresivamente en el plano de la legalidad republicana, como indicó el canónigo Valentín Gómez, destacado diputado de la legislatura de Buenos Aires en 1823: "la marcha general que se sigue es el no constituir de golpe la provincia, sino irla organizando gradualmen-

35 Sobre la trayectoria de García y las reformas económicas del trienio véase Nicolau, 1988. 


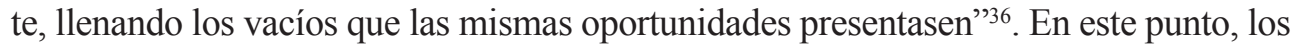
miembros del Partido del Orden siguieron un curso de acción que estaba en sintonía con lo que posteriormente le recomendaría el embajador británico, Woodbine Parish, a Bernardino Rivadavia, al referirse a la futura marcha del congreso constituyente de las provincias rioplatenses reunido a fines de 1824:

El dictado de leyes se hará a medida que vayan siendo necesarias y, por tanto un código se irá estableciendo gradualmente y que se adaptará a las necesidades y circunstancias de la población [...] Yo soy un enemigo de las Constituciones 'listas'. Su perfección es ideal por cuanto nunca, creo yo, han dado resultado al ser aplicadas. Tenemos bastantes ejemplos de su falencia en Francia, España, Nápoles y otras partes de Europa ${ }^{37}$.

La advertencia de Parish recuperaba los sucesivos y fallidos ensayos constitucionales de la Europa continental, incluidos los más recientes nacidos de las revoluciones liberales que a esa altura habían sufrido la reacción de los procesos restauradores, y citaba explícitamente el tortuoso derrotero del área borbónica en contraposición a una estrategia gradual, sometida a las necesidades y circunstancias particulares, que el sistema británico anclado en el Common Law cultivaba desde tiempo inmemorial.

Si la opción gradualista, entonces, encontró en el utilitarismo propiciado por Jeremy Bentham argumentos en los que apoyarse, el autor inglés fue también una cantera inspiradora para implementar herramientas legales y simbólicas que aspiraban a suplir el vacío constitucional; un vacío que afectaba sobre todo a uno de los más caros principios propugnados por el liberalismo en sus diferentes vertientes: el de establecer límites a la autoridad a través del moderno mecanismo de división de poderes. ¿Cómo garantizar dichos límites -ya sea en el repertorio de la más estricta división funcional de poderes o en el de checks and balances adoptado en Estados Unidos- sin contar con las ingenierías que establecían las constituciones surgidas del experimento revolucionario atlántico? La ausencia de una carta orgánica que fijara las atribuciones y límites de los órganos de gobierno fue sustituída por dispositivos que, en la órbita benthamiana, cubrían los vacíos normativos. Dos ejemplos ilustran esta afirmación. El primero remite a la decisión de hacer construir un nuevo edificio para el funcionamiento de la Sala de Representantes de Buenos Aires ${ }^{38}$. Se trataba del primer edificio construido para tal objeto "entre todos los pueblos de América que habían luchado por su emancipación" - -según publicitaba la prensa periódica- y que adoptó la figura del hemiciclo ${ }^{39}$. Su diseño de construcción siguió, según los testimonios, el modelo propuesto por Bentham en su Táctica de las Asambleas Representativas, donde establecía las características más convenientes para alojar a una asamblea numerosa. Dicho modelo buscaba la publicidad de los debates parlamentarios para asegurar con ello la supervisión casi natural del público y difundir al resto de la sociedad el espíritu de

Valentín Gómez, El Centinela, nº 40, 1-V-1823.

Woodbine Parish, Buenos Aires, 20-XII-1824. Piccirilli, 1942: 561.

Sobre el nuevo edificio de la Sala de Representantes véase Aliata, 2006. El autor destaca la rápida resolución del gobierno de erigir un edificio para la nueva institución legislativa y el acelerado proceso de construcción. Señala, además, la poca documentación que existe sobre dicha resolución, informada básicamente a través de la prensa, y cuya primera noticia aparece en el periódico El Argos de Buenos Aires del 25 de agosto de 1821.

39 El Centinela, $\mathrm{n}^{\circ} 13,20-\mathrm{X}-1822$. 
discusión propio de los poderes legislativos ${ }^{40}$. El nuevo recinto estuvo listo en pocos meses. El acto de apertura de las sesiones de 1822 se realizó en el flamante hemiciclo y la prensa periódica exaltó el evento como la inauguración de una nueva era de libertad deliberativa en el principal foro destinado a elaborar las leyes con el aval legitimador de la soberanía popular. El segundo ejemplo lo constituye el Reglamento interno de la Sala de Representantes, aprobado en ese mismo año de 1822, basado también en la recién citada obra de Bentham, según el mismo Rivadavia le confesaba a su inspirador en una misiva: "Verá Ud. Sr., que el reglamento que le adjunto de nuestra Junta de Representantes, que he tenido el honor de proponerle y ha sancionado en una de sus sesiones, está enteramente basado sobre sus irrecusables e inconcusas verdades, contenidas en vuestra obra sobre la Táctica de las Asambleas Legislativas"41. El reglamento estaba constituido por un conjunto de normas minuciosamente detalladas que intentaban, por un lado, asegurar el desarrollo ordenado y racional de la práctica legislativa y la transparencia de los debates parlamentarios, y por el otro, crear barreras para evitar la excesiva intervención ministerial en los asuntos parlamentarios y fijar posiciones respecto de la relación entre el legislativo y el ejecutivo ${ }^{42}$.

A la luz de la dinámica de funcionamiento que adoptaron los poderes legislativo y ejecutivo durante el trienio, cabe destacar que los propósitos del reglamento se vieron cumplidos con creces dada la centralidad que asumió la Sala de Representantes a través de una intensa actividad legislativa que estuvo lejos de mostrar subordinación al ejecutivo. Así lo revelaron los debates por las reformas, donde fue habitual que los proyectos enviados desde el gobierno fueran discutidos, reformulados y enmendados para su definitiva sanción ${ }^{43}$. Reformas que abarcaron casi todos los planos de la realidad política, social y económica: ley electoral; ley de supresión de cabildos; leyes de justicia; ley de supresión de los fueros; ley de imprenta; leyes de creación de ministerios, secretarías y administración; leyes de reforma militar y de milicias; leyes de reforma eclesiástica; ley de enfiteusis; leyes financieras y bancarias; leyes de disciplinamiento social; leyes de regularización territorial urbana y rural, por mencionar las iniciativas más relevantes ${ }^{44}$. En ese vertiginoso proceso legislativo, el principio liberal de limitación del poder político se expresó en un encuadre institucional sui generis, vehiculizado por prácticas configuradas sobre la marcha y sin ajustarse a una constitución del tipo ready made como solía denominar Woodbine Parish a las ingenierías constitucionales tantas veces fracasadas en el continente europeo.

\section{Sociedad y poder político}

El estrecho vínculo que entablaron Rivadavia y Bentham fue, sin duda, una variable importante para dotar de visibilidad a la obra que el exponente de la versión radical del liberalismo británico se esforzaba en difundir. Pero dicha variable no es la única para explicar la presencia utilitarista benthamiana en el trienio bonaerense.

\footnotetext{
40 Bentham, 1838.

41 Carta de Bernardino Rivadavia a Jeremy Bentham. Buenos Aires, 26-VIII-1822. Piccirilli, 1942: 474.

42 "Reglamento y Policía de la Sala de Representantes de la Provincia de Buenos Aires". Silva, 1937: 508-516.

43 Sobre la dinámica de funcionamiento de los poderes entre 1821 y 1824 y las fuentes documentales en las que se apoya el análisis trabajé en detalle en Ternavasio, 2004.

44 Para una perspectiva de síntesis actualizada sobre todo el conjunto de reformas en el período rivadaviano véanse los diferentes capítulos del libro dirigido por Ternavasio, 2013.
} 
Como plantea Beatriz Dávilo, el objetivo de establecer un orden luego de diez años de revolución y guerra requería conjugar en una nueva versión la semántica de los derechos naturales que dominó el período precedente y sobre la cual se montó la justificación de la ruptura con la metrópoli. Superado ese momento, el lenguaje de los derechos mostraba una débil capacidad para reconstruir los lazos de obediencia y gobernabilidad; el lenguaje de la utilidad, en cambio, inscribía el sentido de pertenencia a una sociedad política en el principio de "la mayor felicidad pública posible" y "ofrecía argumentos con mayor fuerza alocutoria para hacer efectivo el reclamo de obediencia" 45 . Desde esta perspectiva, la autora sostiene que el fortalecimiento de la versión liberal utilitarista durante la "feliz experiencia" habría sido producto de las condiciones coyunturales que lo hicieron posible al dotar al gobierno de un criterio que habilitaba a encontrar una base de equilibrio entre libertad y orden, o dicho en otros términos, entre el principio de consentimiento como fundante de la legitimidad de origen y el principio de utilidad como fundante de la legitimidad de ejercicio ${ }^{46}$.

Ahora bien, en esa búsqueda de equilibrio entre libertad y orden, el fenómeno reformista de Buenos Aires no quedó atado exclusivamente a la versión utilitarista inglesa, sino que estuvo abierto a alojar y hacer coexistir diversos lenguajes en pos de replantear las relaciones entre sociedad y poder político. En el marco de dicha tarea es preciso destacar una diferencia significativa, respecto del orden social, que distinguía a la periférica región rioplatense de las que fueron jurisdicciones centrales del imperio español en América y de las sociedades europeas contemporáneas: los promotores de las reformas en el estado de Buenos Aires no debieron enfrentar con el mismo ahínco que en otros espacios una lucha encarnizada contra arraigadas tradiciones corporativas heredadas ni contra una estructura social fundada en severas jerarquías aristocráticas ${ }^{47}$. Esto no significa minimizar el peso de las viejas corporaciones coloniales ni de las jerarquías sociales que dividían a aquella sociedad sino subrayar que la condición marginal que mantuvo la capital del ex virreinato del Río de la Plata hasta fines del siglo XVIII marcó en gran parte su posterior derrotero. Tales diferencias las hacía explícitas el francés Dufresne de Saint Leon, quien le escribía a Rivadavia a fines de 1821, cuando recién comenzaba su gestión de gobierno, para alentarlo en la empresa:

No teneis nobleza; no la tengais jamás [...] Vos sois dueño de un terreno libre, donde no teneis más que construir, mientras que nosotros, debemos todavía sostener una lucha que durará mucho tiempo contra la aristocracia hereditaria que muestra más vigor para defender sus honores puramente nominales, al menos en Francia, que para defender las propiedades y privilegios reales. Vuestra situación es, pues, mucho mejor que la nuestra. Lo que debeis lamentar menos, es la pobreza relativa de la población, que será largo tiempo vuestra tranquilidad, mientras que en nuestro país nuestra población excesiva, al menos en las ciudades, está en un fuerte estado febril, por la superabundancia de hombres que no encuentran tierras para cultivarlas, ni lugar para sus industrias. Está pues con todo, el placer de una esperanza fundada en razonamientos, que contemple los altos y felices destinos de vuestra patria ${ }^{48}$.

45 Dávilo, 2011: 21-22.

46 Ibídem: 26.

47 Véase Roldán, 2005; Palti, 2002; Alonso - Ternavasio, 2011.

48 Carta de Dufresne Saint Leon, Conseiller d'etat honoraire, a Bernardino Rivadavia. París, 30-XII-1821. Piccirilli, 1942: 452 
La extensa cita exhibe las perspectivas de algunas miradas europeas sobre los territorios ultramarinos recién emancipados, en las que la clave de los cambios deseables para quienes integraban la heterogénea familia liberal residía en la composición de las sociedades ${ }^{49}$. Grandes extensiones de territorio, escasa población y ausencia de linajes aristocráticos parecían ser formidables atributos a la hora de modernizar los vínculos entre los estados y las poblaciones sobre las cuales ejercían sus jurisdicciones. Según esta imagen, las dirigencias políticas criollas no tendrían serios obstáculos ni resistencias para avanzar en la aplicación de los nuevos principios que buscaban derribar las herencias del Antiguo Régimen. Una imagen que corroboraba un impreso local, de carácter anónimo, que circuló en Buenos Aires en 1820: "En la nuestra no hay un hábito de distinciones y de clases, y se observa una igualdad de fortunas: hay pocos ricos, pero tampoco hay pobres. El carácter es vivo y dispuesto a la novedad, condiciones excelentes para el adelantamiento y orden republicano"50. A partir de este diagnóstico, que asumían propios y ajenos, es posible explicar dos aspectos centrales del trienio bonaerense que atañen al vínculo entre sociedad y estado: el diseño adoptado para la representación política y la impronta ilustrada que marcó al experimento reformista.

La representación política fue el primer problema al que apuntó la dirigencia para garantizar una gobernabilidad legítima y a la vez ordenada. La sanción de la ley electoral en agosto de 1821 estableció el voto universal masculino y el sistema de elección directa para seleccionar a los diputados de la legislatura que, además, designaban al gobernador a cargo del poder ejecutivo ${ }^{51}$. Si bien los derechos electorales en Hispanoamérica, como ha demostrado Hilda Sabato, se caracterizaron muy tempranamente por gozar de gran amplitud -con momentos de marchas y contramarchas según la región-52, la combinación de un amplísimo derecho de sufragio -que incluía a todos los "hombres libres o avencidados" mayores de 20 años- con voto directo era una fórmula novedosa en el concierto de ensayos representativos a escala atlántica ${ }^{53}$. Una fórmula, a primera vista audaz, que tomaba distancia de aquellas que restringían los derechos electorales o establecían elecciones indirectas en diversos grados para contener las amenazas de la movilización popular; una fórmula en la que parecían converger los postulados de Bentham en defensa del voto universal con los procedentes de los liberales franceses que propugnaban el sistema de elección directa pero con voto calificado, como lo hicieron en ocasión del debate de la ley electoral más importante de la Francia de la Restauración y que Rivadavia presenció en París según indica en su correspondencia ${ }^{54}$.

49 El debate sobre las diversas modulaciones en torno al concepto de "liberalismo" y al adjetivo "liberal" es muy extenso. Para una síntesis sobre tales modulaciones que conectan el caso rioplatense y europeo véanse los artículos que integran el Dossier "Incorporando la historia ajena. Francia, Inglaterra y el Río de la Plata: experiencias e ideas políticas en la primera mitad del siglo XIX”, 2004.

50 Ilustración sobre las causas de nuestra anarquía y del modo de evitarla, firmado por Don F.S y dada a luz por un amigo suyo. Buenos Aires, Imprenta de Phocion, 1820. Archivo General de la Nación [Argentina] (en adelante AGN), Sala 7, Colección Celesia, Impresos 1820, legajo 2472.

51 El tema de la representación política y los procesos electorales en Buenos Aires lo desarrollé en un libro de mi autoría, donde pueden consultarse el aparato heurístico y documental en el que se apoya la investigación, y un análisis detallado en torno a la cuestión republicana, las referencias atlánticas del modelo representativo, y los procesos de selección y toma de decisiones. Ternavasio, 2002.

52 Sabato, 2018.

53 Ley de Elecciones. Buenos Aires, 14-VIII-1821. Recopilación de las Leyes y Decretos promulgados en Buenos Aires desde el 25 de mayo de 1810 hasta fin de diciembre de 1835, primera parte, Buenos Aires, 1836: 173.

54 Carta de Bernardino Rivadavia a Juan Martín de Pueyrredón. París, 22-III-1817. Bernardino Rivadavia. Páginas de un estadista, 1945: 57-58. 
La argumentación de la dirigencia porteña -tanto en la prensa periódica como en la legislatura- para presentar las bondades de la ley electoral se concentró fundamentalmente en los beneficios que acarrearía el voto directo, replicando y citando a Benjamin Constant, uno de los máximos representantes del liberalismo francés y cuya obra, Principios de Política, circulaba a esa altura entre la elite letrada y política ${ }^{55}$. Los hacedores de la ley consideraban que la dimensión más sobresaliente del nuevo sistema representativo era la eliminación de las juntas electorales del régimen indirecto vigente durante la década precedente, tal como reconocía el periódico El Centinela, apenas un año después de aplicarse la ley electoral:

Diferentes leyes de elecciones se han dictado en el curso de la revolución; más solamente una, esto es la que actualmente rige, sancionada en el año de 1821, es la que ha puesto al pueblo en el pleno goce de su derecho de elegir, porque según dicha ley ninguna voluntad intermedia se interpone entre la del pueblo y el cuerpo representativo -quiere decir que la elección es directa como en los Estados Unidos. Este gran paso dado en favor de la mayor seguridad y acierto en las elecciones populares, ha puesto al pueblo a cubierto de las pretensiones de los facciosos recopilados en las juntas electorales, para hacer o la voluntad de sus patronos a quienes podían venderse porque eran pocos, o cuando mucho favor se les haga, la suya propia con abandono total de la voluntad de sus comitentes ${ }^{56}$.

Para la elite letrada y política porteña, el gesto innovador era el voto directo y no el amplio derecho de sufragio, al que no le dieron un papel relevante en el discurso público. Por el contrario, lo que imperó fue más bien el silencio o la naturalización de la ausencia de restricciones al voto, como argumentó la comisión redactora de la ley electoral al expedirse sobre el proyecto aprobado en la Sala de Representantes:

Fuera de los esclavos, hay también una clase de hombres que reunidos por la indigencia en una dependencia absoluta, no son más inteligentes que los niños en los negocios públicos, ni más interesados que los extranjeros, ni más independientes quizá que los esclavos. La imperfección de la ciencia del gobierno no encontraba una regla fija que demarcase bien estas diferencias, y quedaba así un vacío de que se aprovechaba unas veces la aristocracia de los ricos y poderosos [...] y otras veces los demagogos [...] La garantía deseada contra estos dos extremos parece haberse encontrado en la condición de propiedad para ser elegido representante ${ }^{57}$.

El carácter inclusivo del sufragio no aparecía, entonces, como una voluntad radical sino como una derivación de la ausencia de una "regla fija" que, no obstante, estaba compensada con la restricción de la calidad de los elegidos a "todo ciudadano mayor de 25 años, que posea alguna propiedad inmueble, o industrial", siguiendo en este punto el guión de todos los sistemas electorales conocidos que distinguía las

\footnotetext{
Constant, [1815] 1989.

El Centinela, n 21, 15-XII-1822.

Minuta de decreto que establece las condiciones necesarias para elegir y ser elegido miembro de la H.J. de Representantes y prescribe el orden y método de las elecciones. Buenos Aires, Imprenta de la Independencia, agosto de 1821. AGN, Sala 7, Colección Celesia, Impresos 1821-1823, leg. 2474.
} 
condiciones de electores y elegibles ${ }^{58}$. La implementación de la ley de sufragio fue un globo de ensayo sobre el que nadie tenía certezas acerca de sus resultados en el corto y mediano plazo. Por los escasos testimonios que tenemos del momento en que fue sancionada podemos inferir que con ella se pretendían atacar dos "males" heredados de la política revolucionaria, según el diagnóstico del nuevo gobierno. El primero residía en las disputas facciosas dentro de la elite dirigente. La expectativa era que con el voto directo se podía eliminar uno de los escenarios en los que esas disputas se desplegaban: los colegios electorales. El segundo estaba representado por el escaso número de votantes que asistían a los comicios y la consecuente deslegitimación de las autoridades, cuestionadas con frecuencia por movimientos asambleístas que en nombre del ejercicio directo de la soberanía se arrogaban el derecho de derrocar a las autoridades electas por sufragio. En este caso, la expectativa apuntaba a multiplicar el número de electores para obtener una legitimidad que resultara irreprochable; una legitimidad numérica que requería establecer un amplio derecho de voto y eliminar uno de los principales escenarios en los que se convocaban y desplegaban las asambleas populares: los cabildos ${ }^{59}$.

La ley de supresión de los dos ayuntamientos existentes en la provincia, sancionada cuatro meses después de la ley electoral, se propuso entonces el doble objetivo de erradicar los resabios coloniales y, sobre todo, de desarticular el vínculo que los antiguos cabildos establecieron con los pueblos a partir de la crisis de la monarquía. Esta medida también resultaba inédita en el concierto hispanoamericano, habida cuenta que no estuvo acompañada por la reconversión de los ayuntamientos en órganos municipales de nuevo tipo. El diseño representativo buscó así consolidar el moderno criterio de que el pueblo como titular de la soberanía la delegaba en el cuerpo de representantes y reemplazar la desordenada movilización popular que encontraba en los cabildos el anclaje institucional para sus reclamos. Legitimar a las autoridades fue, en este sentido, la piedra angular para dotar de estabilidad al naciente estado bonaerense y para salir de la crisis política devastadora que sufrió la provincia a lo largo de 1820. La apuesta por el orden se vehiculizó, pues, por la vía heterodoxa de promover desde el gobierno la amplia participación de la ciudadanía en las elecciones y las libertades de expresión, de imprenta y de asociación.

El optimismo que parecía subtender a todas estas medidas, y que demostraron tener éxito en el corto plazo, nos conduce a la mencionada impronta ilustrada sobre la que llamó la atención Jorge Myers al postular la hipótesis de un fuerte dominio de la Ilustración en las reformas del trienio -impronta que el autor denomina incluso como "neoborbónica"- en la que se entrelazaron discursos y principios liberales del utilitarismo, la ideologie o el liberalismo francés sin estar ausentes los tópicos republicanos clásicos actualizados durante el proceso revolucionario ${ }^{60}$. La convivencia ecléctica de estas ideas no era ajena a la convicción del elenco político y letrado que integró el gobierno de que el motor de los cambios deseables no podía proceder de una sociedad que debía ser antes educada en el camino civilizatorio para convertirse en lo que el liberalismo tenía como presupuesto de partida al postular que la sociedad era el sostén del orden político.

\footnotetext{
58 Ley de Elecciones, Buenos Aires, 14-VIII- 1821. Recopilación de las Leyes y Decretos promulgados en Buenos Aires desde el 25 de mayo de 1810 hasta fin de diciembre de 1835, primera parte, Buenos Aires, 1836: 174.

59 Sobre la supresión de los cabildos de Buenos Aires véase Ternavasio, 2000.

60 Myers, 1998: 31-36.
} 
Ante la imagen de debilidad del entramado social, la elite dirigente se propuso modelarlo según sus objetivos y estimular "desde arriba" formas de sociabilidad y asociaciones privadas compatibles con la idea moderna de individuo autónomo ${ }^{61}$. En estas asociaciones se desarrollaría el aprendizaje de la deliberación racional, se modernizarían las costumbres y se expandiría la pedagogía cívica que requerían las reformas para afianzar el espíritu republicano ${ }^{62}$. Pero esas mismas asociaciones que se postulaban como centros capaces de obrar "con absoluta independencia de los partidos o de los gobiernos" -según anunciaba el acta fundacional de la Sociedad Literaria creada en Buenos Aires en 1822- estaban conformadas por los mismos miembros del poder político o sectores de la elite muy vinculados a ellos ${ }^{63}$. Como indica Myers, la paradoja que recorrió al experimento rivadaviano fue que "aquellos elementos inmanentes a la sociedad sobre los cuales se apoyaría el nuevo orden estatal no poseían aún ninguna existencia real y que le competía, pues, a ese mismo Estado la tarea de establecerlos" ${ }^{4}$. En esa sintonía, la representación política vehiculizada a través de la ley electoral era también un artefacto que pretendía modelar los vínculos entre las bases sociales del amplio segmento de gobernados y las elites gobernantes, bajo el presupuesto de que las segundas podrían conducir a las primeras hacia la cultura republicana que aspiraban imponer.

La intersección entre lenguajes liberales e ilustrados no fue, como sabemos, un fenómeno excepcional de la periférica Buenos Aires ${ }^{65}$. Si bien sus entrelazamientos siguen siendo foco de exploración y debate en el mundo iberoamericano de esos años, cabe subrayar lo que Beatriz Dávilo señaló al interrogarse acerca de cuál era el liberalismo que impregnó al pequeño grupo de letrados y dirigentes porteños del trienio ${ }^{66}$. En su respuesta sugiere que el caso podría asimilarse al liberalismo ibérico de la segunda década del siglo XIX que, según Javier Fernández Sebastián y Juan Francisco Fuentes, resultaba de la articulación entre iusnaturalismo y utilitarismo donde el reconocimiento del valor político de la libertad se combinaba con un rol central asignado al Estado como motor de la transformación social ${ }^{67}$. Una hipótesis de lectura que estaría en línea con la cita inicial de Desttut de Tracy, quien supo develar tempranamente, y no sin sorpresa, que el gobierno de Buenos Aires era más liberal que los gobernados.

\section{Conclusión}

Mirado desde una perspectiva transatlántica, el caso de Buenos Aires aquí analizado formó parte de ese clima de intercambios, circulaciones y migraciones que los simultáneos acontecimientos ocurridos a partir de 1820 colaboraron a intensificar. Las conexiones creadas en los años precedentes y las diferentes situaciones en los puntos de partida explican las diversas variantes que en esos años se modularon en el mundo ibérico euroamericano. En el marco de esas variantes, la diferencia más obvia es que

\footnotetext{
Ibídem, 1999.

Sobre el asociacionismo en este período véase González Bernaldo, 1999.

Introducción a las actas de la Sociedad Literaria de Buenos Aires, 1822. Rodríguez, 1921: 285.

Myers, 1998: 44.

${ }^{65}$ Sobre esta confluencia para los procesos reformistas hispanoamericanos de las décadas de 1820 y 1830, véase Ávila, 2011.

66 Dávilo, 2011: 218.

${ }^{67}$ Fernández Sebastián - Fuentes, 2002: 413-429.
} 
la articulación entre liberalismo y formas de gobierno declinó en España y Portugal, y luego en el independiente Imperio de Brasil, en molde monárquico constitucional, mientras que en Hispanoamérica lo hizo en molde republicano, con la excepción de la efímera experiencia imperial mexicana de Iturbide. Como ha observado Alfredo Ávila, los radicalismos republicanos que se observan desde el Río de la Plata hasta México pasando por Colombia y Centroamérica entre las décadas de 1820 y 1830 presentan problemas y respuestas comunes ante el mismo objetivo de erradicar los hábitos coloniales y la cultura política de las sociedades ${ }^{68}$. Clément Thibaud, por su parte, plantea que el carácter anti-imperial del republicanismo hispanoamericano explica, en gran parte, su temprana asociación con el liberalismo y los efectos de retorno que produjo hacia Europa y el Mediterráneo desde 1820 en adelante ${ }^{69}$.

En esos contextos, la exigencia constitucional liberal que fomentó la creación de un espacio de circulación cosmopolita se tramitó en las dos monarquías ibéricas del trienio a través del gesto radical de exigir a sus monarcas jurar y gobernar como reyes constitucionales. Revolución y constitución emergían allí como un binomio necesario para poner fin al absolutismo y al Antiguo Régimen y como punta de lanza del principio liberal de limitación del poder de la autoridad política. En la experiencia rioplatense, en cambio, el mismo bimonio asumió para las dirigencias que declararon la independencia un sentido diferente: la constitución debía venir a "poner fin a la revolución, principio al orden", según estableció el decreto sancionado por el Congreso pocos días después del acta de emancipación de 1816. Como ha destacado Natalio Botana, lo que subtendía a la aspiración constitucional de los diputados de aquella asamblea era una voluntad constructivista en torno a la forma de gobierno como cimiento de la nueva libertad y del orden deseable ${ }^{70}$. En tal sentido, la constitución no representaba tanto un instrumento destinado a limitar el poder de las autoridades sino un proyecto constructivista de la nueva y desmembrada soberanía surgida del colapso de la monarquía española. Darío Roldán ha destacado, en esta dirección, que el omnipresente debate en torno al sujeto de imputación de la soberanía en el Río de la Plata planteaba la paradoja de no haber sido dicha soberanía objeto de crítica ni contrastada con principios introducidos en otras geografías que, luego de experiencias más o menos anárquicas o despóticas, buscaban limitar y condicionar su ejercicio ${ }^{71}$.

La dimensión constructivista que subtiende a los fracasados proyectos constitucionales rioplatenses durante la década revolucionaria, signados por las disputas en torno a las formas centralistas o (con)federales de gobierno, no deja de tener un parecido de familia con la voluntad que mostraron los liberales en las Cortes de Cádiz, cuando la carta finalmente sancionada en 1812 buscó no solo limitar el poder del monarca todavía cautivo sino también, y fundamentalmente, como plantea José María Portillo, reconstituir el fideicomiso de la soberanía a escala bioceánica que había provocado la crisis monárquica a través de la "revolución de nación"; una voluntad que, al menos para una parte de los territorios ultramarinos, parecía quimérica en el segundo ensayo constitucional de $1820^{72}$. Pero el nuevo clima creado durante ese año en el Río de la Plata, signado tanto por el fracaso constituyente y el colapso del poder

\footnotetext{
Ávila, 2011: 29.

Thibaud, 2019: 147.

Botana, 2016: 184.

Roldán, 2003: 41.

Portillo Valdés, 2000.
} 
central como por la distensión que provocó el pronunciamiento de Riego al clausurar la amenazante expedición de reconquista a Buenos Aires, habilitó a la naciente república de Buenos Aires a desplazar y dejar en suspenso el problema del sujeto de imputación de la soberanía y transitar la vía heterodoxa que implicó poner en práctica un gobierno limitado sin atar a sus gobernantes a un modelo constitucional estandarizado que podía restarles flexibilidad en la empresa reformista.

Las referencias citadas apuntan a concluir que la inflexión ocurrida con la primera oleada de revoluciones liberales en Europa y los primeros ensayos reformistas americanos marcó derroteros en los que, a pesar de las diferencias y particularidades, convergieron problemas comunes y respuestas adaptadas a las expectativas y dilemas de cada país y región. En este sentido, Maurizio Isabella destaca que, en toda la cuenca mediterránea, las revoluciones liberales del trienio articularon al debate constitucional la cuestión de las libertades y autonomías territoriales frente al tema de la centralización $^{73}$. Y a pesar de la distancia que separa a esos ensayos del Río de la Plata, la clausura de la "feliz experiencia" estuvo marcada por la convocatoria a un nuevo congreso constituyente de todas las provincias, reunido a fines de 1824 en Buenos Aires, en el que regresó con toda su potencia la antinomia centralización/descentralización. En el nuevo escenario que venía, finalmente, a nacionalizar el cuerpo político fragmentado cuatro años antes, gran parte de la dirigencia que lideró la "feliz experiencia" procuró dominar el futuro diseño de una república unificada sancionando en 1826 una constitución centralista que fue rechazada por la mayoría de las provincias. Autogobierno territorial versus centralización fueron aquí también los ejes del debate constitucional y el dilema irresuelto del frustrado intento constituyente.

El fracaso de crear una república unificada reflejaba las dificultades que imponía pasar de una escala provincial a una nacional para proyectar los vínculos deseables y posibles entre constitución y territorios y entre sociedad y estado. La misma elite política que promovió el proceso reformista entre 1821 y 1824 no replicó en el congreso sus encendidas arengas en defensa de la participación ciudadana a través del voto de todos los hombres libres, de la libre deliberación en el espacio público y de las necesarias barreras para garantizar la limitación del poder. Por el contrario, postuló restringir el derecho de sufragio, debatir los límites de las polémicas en la prensa y establecer un poder central robusto y enérgico encarnado en el poder ejecutivo nacional. La ampliación del espacio político que incluía al resto de las provincias condujo al grupo rivadaviano a desoír los consejos gradualistas del embajador Parish y a lanzarse a una estrategia del todo o nada. Regresaba así la cosmovisión constructivista de la constitución, con el objeto de restituir una unidad soberana allí donde las provincias reclamaban en nombre de los pueblos el derecho al autogobierno, subtendida por la idea iluminista de que las sociedades no estaban preparadas para ejercer tales derechos y que requerían de un estado potente para encauzarlas en el camino civilizatorio.

\section{Referencias bibliográficas}

Agüero, Alejandro. “¿Provincias o estados? El concepto de provincia y el primer constitucionalismo provincial rioplatense. Un enfoque ius histórico". Revista de Historia Americana y Argentina, vol. 54, $\mathrm{n}^{\mathrm{o}} 1$ (2019), 137-175.

73 Isabella, en prensa. 
Aliata, Fernando. La ciudad regular: arquitectura, programas e instituciones en el Buenos Aires posrevolucionario, 1821-1835. Bernal: Ediciones UNQ, 2006.

Alonso, Paula - Ternavasio, Marcela. "Liberalismo y ensayos políticos en el siglo XIX". En Liberalismo y Poder. Latinoamérica en el siglo XIX, editado por Jaksic, Iván - Posada Carbó, Eduardo. Santiago de Chile: Fondo de Cultura Económica, 2011, 279-320.

Ávila, Alfredo. "El radicalismo republicano en Hispanoamérica: un balance historiográfico y una propuesta de estudio". Estudios de Historia Moderna y Contemporánea de México, $\mathrm{n}^{\circ} 41$ (2011), 29-52.

Bentham, Jeremy. Traité de législation civile et pénal. París: Bossange, 1802.

- Colonies, commerce and constitutional law: Rid yourself Ultramaria and other writings on Spain and Spanish America [1820]. Oxford: Clarendon Press, 1995.

- Táctica de las Asambleas Legislativas. París: Imprenta Pillet Ainé, 1838.

Bernardino Rivadavia. Páginas de un estadista. Buenos Aires: Elevación, 1945.

Botana, Natalio. Repúblicas y Monarquías. La encrucijada de la independencia. Buenos Aires: Edhasa, 2016.

Chiaramonte, José Carlos. Ciudades, provincias, Estados: Orígenes de la Nación Argentina (1800-1846). Buenos Aires: Ariel, 1997.

Constant, Benjamín. Principios de Política [1815]. Madrid: Centro de Estudios Constitucionales, 1989.

Dávilo, Beatriz. Los derechos, las pasiones, la utilidad. Debate intelectual y lenguajes políticos en Buenos Aires (1810-1827). Buenos Aires: EDUNTREF, 2011.

Documentos inéditos acerca de la misión del Dr. D. Manuel José García diputado de las "Provincias Unidas en la Corte del Janeiro. Buenos Aires: Imprenta de J. A. Alsina, 1883.

Dossier "Incorporando la historia ajena. Francia, Inglaterra y el Río de la Plata: experiencias e ideas políticas en la primera mitad del siglo XIX”. Estudios Sociales, n 26 (2004), 119-192.

El Censor Americano. Santiago de Chile: Centro de Investigaciones Diego Barros Arana Biblioteca Nacional de Chile, 2019.

Entin, Gabriel. "República y Federalismo en América del Sur, entre la Monarquía hispánica y las revolcuiones de independencia". En Entre el Mediterráneo y el Atlántico.Circulaciones, conexiones, miradas, 1756-1867, editado por De Francesco, Antonino - Migliorini, Luigi - Nocera, Raffaele. Santiago de Chile: Fondo de Cultura Económica, 2014, 363-392.

Fernández Sebastián, Javier - Fuentes, Francisco (dirs.). Diccionario político y social del siglo XIX español. Madrid: Alianza editorial, 2002.

— "Liberales sin fronteras. Cádiz y el primer constitucionalismo hispánico". En Cadice e oltre:constituzione, nazione e liberta, editado por García Sanz, Fernando - Scotti Douglas, Vittorio - Ugolini, Romano - Urquijo Goitia, José. Roma: Instituto per la Storia del Risorgimento italiano, 2015, pp. 465-490.

Gallo, Klaus. Bernardino Rivadavia. El primer presidente argentino. Buenos Aires: Edhasa, 2012.

Goldman, Noemí. "Formas de gobierno y opinión pública, o la disputa por la acepción de las palabras, 1810-1827". En La vida política en la Argentina del siglo XIX. Armas, votos $y$ voces, editado por Sabato, Hilda - Lettieri, Alberto. Buenos Aires: Fondo de Cultura Económica, 2003, 45-56.

González Bernaldo. Pilar. Civilité et Politique. Aux origines de la Nation Argentine. París: Sorbonne, 1999.

Halperin Donghi, Tulio. Revolución y guerra. Formación de una elite dirigente en la Argentina criolla. México: Siglo XXI, 1979. 
Isabella, Maurizio. Risorgimento in exile: Italian émigrés and the Liberal International in the Post-Napoleonic Era. Oxford: Oxford University Press, 2009.

- "Las revoluciones en el Mediterráneo como crisis territoriales. Constituciones en España, Piamonte, Nápoles, Sicilia y Grecia”. En El Trienio Liberal en España y América (18201823): balance y perspectivas, editado por Rújula, Pedro - Frasquet, Ivana [en prensa].

Myers, Jorge. "La cultura literaria del período rivadaviano: saber ilustrado y discurso republicano". En Carlo Zucchi y el neoclasicismo en el Río de la Plata, editado por Aliata, Fernando - Munilla Lacasa, María Lía. Buenos Aires: Eudeba, 1998, 31-48.

- "Una revolución en las costumbres: las nuevas formas de sociabilidad de la elite porteña, 1800-1860". En Historia de la vida privada en la Argentina. País antiguo: de la colonia a 1870, tomo I, editado por Devoto, Fernando - Madero, Marta. Buenos Aires: Taurus, 1999, 111-146.

Nicolau, Juan Carlos. La reforma económico-financiera en la provincia de Buenos Aires (18211825). Liberalismo y economía. Buenos Aires: Fundación Banco Provincia de Buenos Aires, 1988.

Palti, Elías. "Las polémicas sobre el liberalismo argentino. Sobre virtud, republicanismo y lenguaje”. En El republicanismo en Hispanoamérica. Ensayos de historia intelectual y política, editado por Aguilar Rivera, José Antonio - Rojas, Rafael. México: Fondo de Cultura Económica-CIDE, 2002, 167-209.

Piccirilli, Ricardo. Rivadavia y su tiempo. Peuser: Buenos Aires, 1942.

Pimenta, João Paulo. La independencia de Brasil y la experiencia hispanoamericana (18081822). Santiago de Chile: Dibam/Centro de Investigaciones Diego Barros Arana, 2017.

Polastrelli, Irina. Castigar la disidencia. Juicios y condenas en la elite dirigente rioplatense 1806/1808-1820. Buenos Aires: Academia Nacional de la Historia, 2019.

Portillo Valdés, José María. Revolución de nación: orígenes de la cultura constitucional en España, 1780-1812. Madrid: Centro de Estudios Políticos y Constitucionales, 2000.

Recopilación de las Leyes y Decretos promulgados en Buenos Aires desde el 25 de mayo de 1810 hasta fin de diciembre de 1835. Buenos Aires, 1836.

Registro Oficial de Buenos Aires. Buenos Aires, Imprenta de la Independencia, Libro $1^{\circ}$, 1821.

Rodríguez, Gregorio. Contribución Histórica y Documental. Buenos Aires: Peuser, 1921.

Roldán, Darío. "La cuestión de la representación en el origen de la política moderna. Una perspectiva comparada (1770-1830)". En La vida política en la Argentina del siglo XIX. Armas, votos y voces, editado por Sábato, Hilda - Lettieri, Alberto. Buenos Aires: Fondo de Cultura Económica, 2003, 25-44.

- La question libérale en Argentine au XIX siècle. Paris: Université Paris VIII, 2005.

Ruiz Ruiz, Juan José “'Antisenática' en el Trienio Liberal (1820-1823): Bentham contra la introducción del bicameralismo en España”. Revista de Estudios Políticos, $\mathrm{n}^{\circ} 123$, (2004), 351-391.

Sabato, Hilda. Republics of the New World. The revolucionary political experiment in nineteenth Latin America. Princeton: Princeton University Press, 2018.

Saguir, Julio. Una grieta de doscientos años. Conflictos y debates constituyentes en la Argentina (1816-1827). Buenos Aires: Prometeo, 2020.

Silva, Carlos. El Poder Legislativo de la Nación Argentina, tomo I. Buenos Aires: Cámara de Diputados de la Nación, 1937.

Ternavasio, Marcela. "La supresión del Cabildo de Buenos Aires, ¿crónica de una muerte anunciada?". Boletín del Instituto de Historia Americana y Argentina "Dr. Emilio Ravignani", $\mathrm{n}^{\mathrm{o}} 21$ (2000), 33-73. 
- La revolución del voto. Política y elecciones en Buenos Aires, 1810-1852. Buenos Aires: Siglo XXI, 2002

— "Construir poder y dividir poderes. Buenos Aires durante la 'feliz experiencia' rivadaviana". Boletín del Instituto de Historia Americana y Argentina "Dr. Emilio Ravignani”, n” 26 (2004), 7-43.

- Gobernar la revolución. Poderes en disputa en el Río de la Plata, 1810-1816. Buenos Aires: Siglo XXI, 2007.

- Historia de la Argentina, 1806-1852. Buenos Aires: Siglo XXI, 2009.

Ternavasio, Marcela (dir.). Historia de la provincia de Buenos Aires. De la organización provincial a la federalización de Buenos Aires (1821-1880). Buenos Aires: UNIPE-Edhasa, 2013.

Thibaud, Clément. "Para una historia policéntrica de los republicanismos atlánticos (17701880)". Prismas. Revista de Historia Intelectual, ${ }^{\circ} 23$ (2019), 145-162. 